\title{
Human lysozyme as a potential diagnostic marker in malaria: a mechanistic study of haemozoin- induced monocyte degranulation
}

\author{
Manuela Polimeni ${ }^{1}$, Elena Valente ${ }^{1}$, Elisabetta Aldieri ${ }^{1}$, Amina Khadjavi ${ }^{1}$, Giuliana Giribaldi ${ }^{1}$, Mauro Prato ${ }^{1,2^{*}}$ \\ From Challenges in malaria research \\ Basel, Switzerland. 10-12 October 2012
}

\begin{abstract}
Background
Lysozymes are antibacterial proteins defined by their ability to hydrolyse beta-1,4-glycosidic linkage between $\mathrm{N}$-acetylmuramic acid and $\mathrm{N}$-acetylglucosamine of peptidoglycan in the cell wall of bacteria [1]. In the recent years, little evidence on their involvement in malaria pathogenesis has emerged. In Anopheles gambiae and stephensi, lysozyme was shown to bind to oocysts of Plasmodium berghei and falciparum, thereby facilitating their development within the mosquito [2]. In human patients, lysozyme plasma levels correlated significantly to parasitaemia degree, suggesting its potential role as marker of disease severity [3]. In this context, phagocytosis of haemozoin (HZ, malarial pigment) was shown in a previous work to induce in vitro lysozyme release from human monocytes [4]; here, the underlying mechanisms were investigated.
\end{abstract}

\section{Materials and methods}

Human adherent monocytes from healthy donors were allowed to phagocytose for $2 \mathrm{~h}$ natural $\mathrm{HZ}$ isolated from Plasmodium falciparum cultures; after the end of phagocytosis, cells were incubated for 2 additional $\mathrm{h}$ in the presence or absence of: anti-TNFalpha/IL-1beta/MIP-1alpha blocking antibodies; recombinant TNFalpha/IL-1beta/ MIP-1alpha; p38 MAPK inhibitor (SB203580); NF-kappaB inhibitors (quercetin, artemisinin, and parthenolide). Thereafter, lysozyme levels in cell supernatants were evaluated by measuring lysis of Mycrococcus Lysodeikticus suspensions through spectrometry, and TNFalpha, IL-1beta, and MIP-1alpha levels by ELISA. In cell lysates, p38

'Dipartimento di Genetica, Biologia e Biochimica, Facoltà di Medicina e

Chirurgia, Università degli Studi di Torino, Torino, 10126, Italy

Full list of author information is available at the end of the article
MAPK and NF-kappaB pathways were investigated by Western blotting or EMSA.

\section{Results}

$\mathrm{HZ}$ promoted a time-dependent release of lysozyme, along with TNFalpha, IL-1beta and MlP-1alpha. HZinduced lysozyme release was abrogated by anti-TNFalpha/IL-1beta/MIP-1alpha blocking antibodies, and mimicked by all three recombinant cytokines. Moreover, HZ early activated either p38 MAPK or NF-kappaB pathways by inducing: p38 MAPK phosphorylation; cytosolic I-kappaBalpha phosphorylation and degradation; NF-kappaB nuclear translocation and DNA-binding. Inhibition of both routes prevented HZ-dependent lysozyme release.

\section{Conclusions}

These data suggest that the HZ-triggered overproduction of TNFalpha, IL-1beta and MlP-1alpha mediates induction of lysozyme release from human monocytes through activation of $\mathrm{p} 38$ MAPK and NF-kappaB pathways. Therefore, the present work provides new evidence on the mechanisms underlying HZ-enhanced monocyte degranulation in falciparum malaria, supporting the hypothesis that lysozyme could be used as a new affordable marker in severe malaria.

\section{Acknowledgments}

This study was supported by Intramural Funds from Università degli Studi di Torino to Giuliana Giribaldi, and by Charity Funds from Mrs. Franca Squazza to Mauro Prato. The funders had no role in study design, data collection and analysis, decision to publish, or preparation of the manuscript.

\section{Author details}

${ }^{1}$ Dipartimento di Genetica, Biologia e Biochimica, Facoltà di Medicina e Chirurgia, Università degli Studi di Torino, Torino, 10126, Italy. 
${ }^{2}$ Dipartimento di Neuroscienze, Facoltà di Medicina e Chirurgia, Università degli Studi di Torino, Torino, 10125, Italy.

Published: 15 October 2012

\section{References}

1. Callewaert $L$, Michiels CW: Lysozymes in the animal kingdom. J Biosci 2010, 35:127-160.

2. Kajla MK, Shi L, Li B, Luckhart S, Li J, Paskewitz SM: A new role for an old antimicrobial: lysozyme c-1 can function to protect malaria parasites in Anopheles mosquitoes. PLoS One 2011, 6:e19649.

3. Mohamed AO, Elbashir MI, Ibrahim G, Ismail M, Venge P: Neutrophil leucocyte activation in severe malaria. Trans R Soc Trop Med Hyg 1996, 90:277.

4. Prato $M$, Giribaldi $G$, Arese P: Hemozoin triggers tumor necrosis factor alpha-mediated release of lysozyme by human adherent monocytes: new evidences on leukocyte degranulation in P. falciparum malaria. Asian Pac J Trop Med 2009, 2:35-40.

doi:10.1186/1475-2875-11-S1-P80

Cite this article as: Polimeni et al: Human lysozyme as a potential diagnostic marker in malaria: a mechanistic study of haemozoininduced monocyte degranulation. Malaria Journal 2012 11(Suppl 1):P80.

\section{Submit your next manuscript to BioMed Central} and take full advantage of:

- Convenient online submission

- Thorough peer review

- No space constraints or color figure charges

- Immediate publication on acceptance

- Inclusion in PubMed, CAS, Scopus and Google Scholar

- Research which is freely available for redistribution

Submit your manuscript at www.biomedcentral.com/submit 